\title{
An evaluation of photoelectric haemoglobinometers
}

\author{
S. M. LEWIS with the technical assistance of B. J. B URGESS
}

From the Department of Haematology, Royal Postgraduate Medical School, London

SYNOPSIS A number of photoelectric haemoglobinometers have been evaluated as to their suitability for haemoglobinometry in the routine clinical laboratory. They have been tested for accuracy, precision, linearity of response, instrument comparability and, where relevant, for carry-over. The advantages and defects of each are described.

As a project of the British Committee for Standards in Haematology, and at the request of the Laboratory Equipment and Methods Advisory Group of the Department of Health and Social Security, a number of photoelectric haemoglobinometers that are currently available in the United Kingdom have been tested and evaluated as suitable for clinical haemoglobinometry in the routine laboratory. Manufacturers or their agents were invited to provide, on short-term loan, instruments as available from stock, ready for delivery to the customer. On receipt the instruments were assembled in accordance with the operating instructions provided. Then, over a period of three to four weeks, their performance was assessed by established methods for accuracy, precision, instrument comparability, and when relevant, for carry-over and sample crosscontamination. For evaluation of accuracy and precision, haemoglobin (as cyanmethaemoglobin) was determined repeatedly on five specimens over a wide range of haemoglobin concentrations. In some of the runs the samples were handled sequentially, in others they were interspersed with routine specimens in a batch. For instrument comparability a batch of routine specimens was measured in the instrument under test and in a conventional photoelectric colorimeter of known reliability. Accuracy was assessed by measuring the haemoglobin concentration of the test samples

Received for publication 4 May 1970. with a spectrophotometer which had been calibrated in accordance with the recommendations of the International Committee for Standardization in Haematology (1967). In order to determine linearity of response of the galvanometer, optical density was recorded with progressive dilution of cyanmethaemoglobin. The result given is the mean of measurements of four samples. Total carryover was measured only in instruments with automatic sampling units by determining the influence of (a) a high-concentration specimen on (b) a subsequent low-concentration specimen. Three tests were carried out consecutively, first on specimen $a\left(a_{1}, a_{2}, a_{3}\right)$ and then on specimen $b$ $\left(b_{1}, b_{2}, b_{3}\right)$, and the carry-over was expressed as $k=\frac{b_{1}-b_{3}}{a_{3}-b_{3}}$. Routinely, specimens were diluted in Van Kampen-Zijlstra's cyanide-ferricyanide reagent $(p \mathrm{H} \mathrm{7 \cdot 2)}$ (International Committee for Standardization in Haematology, 1967) and measurement was delayed for at least five minutes to ensure complete conversion. This reagent contains a non-ionic detergent. In some instances parallel tests were carried out using the cyanide-ferricyanide reagent without detergent at a pH of 9.6 (Lewis, 1967). For these tests measurement was delayed for at least 15 minutes. In general, identical results were obtained with both reagents, but where differences did occur this will be noted in the relevant section below.

Some of the instruments are intended speci- 
fically for haemoglobinometry, whereas others are general-purpose photoelectric colorimeters. They have, however, been evaluated only with regard to their use as haemoglobinometers, and it should be emphasized that the standard of performance which was considered acceptable was that required for routine clinical haemoglobinometry. In this report the analytic data have been summarized. Detailed protocols of results are available.

\section{EEL Haemoglobinometer}

Evans Electroselenium Ltd, Halstead, Essex (£78).

\section{DESIGN}

This is a sturdy instrument, $33 \times 18 \mathrm{~cm}$ in area, made of cast aluminium. Operation is manual. The controls are easily accessible. Cuvettes are optically matched test tubes which have a capacity of 4 to $6 \mathrm{ml}$ and a light path of $12 \mathrm{~mm}$; single beam with tungsten filament. Haemoglobin is read directly as oxyhaemoglobin or cyanmethaemoglobin on adjacent scales. The scales are cramped in the 13-18 g/100 ml region. Standardization is relatively complex by means of a 'high standard' (18 g/100 ml) and a 'low standard' $(3 \mathrm{~g} / 100 \mathrm{ml})$ which have to be used consecutively. For setting the instrument for oxyhaemoglobin measurement wholeblood 'standards' are required; calibration for cyanmethaemoglobin measurement requires cyanmethaemoglobin solutions of the appropriate concentrations as indicated. There is a relatively long stabilization time of $\mathbf{3 0}$ minutes, after which the instrument remains stable with negligible drift during the course of the day. There is, however, risk of accidental movement of the standard control knobs which cannot be locked after they have been set. The instrument casing is designed to hold tubes of high and low standards, intended for use during the day. However, these become heated by the instrument lamp and are thus liable to deterioration.

\section{COMMENTS}

Only cyanmethaemoglobin reference preparations in a concentration of 55 to $85 \mathrm{mg} / 100 \mathrm{ml}$ conform to the specifications established by ICSH (1967). When intended for cyanmethaemoglobin measurements this haemoglobinometer requires, for its calibration, the use of cyanmethaemoglobin preparations of high and low concentrations which are outside this range and which are not subject to the rigid control which can be applied to preparations which do conform to the ICSH recommendations. Furthermore, if used for oxyhaemoglobin measurement, calibration requires whole blood 'standards' of uncertain reliability (Dacie and Lewis, 1968), which ma $\frac{\curvearrowright}{\bar{y}}$ result in serious error if they have not maintained their reputed values. In the evaluation of the haemoglobinometer the tests indicated an unsatisfactory level of accuracy. To be certain that this was not due to discrepancies in the 'standaro" preparations used for calibrating the instrument these were checked against the ICSH cyanmethae moglobin reference preparations and were show to be true to their reputed concentrations. Hence the poor performance was apparently inherent if the instrument. The presence of the two scales fos cyanmethaemoglobin and oxyhaemoglobin respectively adjacent to each other is a potentify source of reading error and confusion, and the method of calibration is unnecessarily complp cated.

SUMMARY OF ANALYTIC DATA (HAEMO GLOBIN MEASURED AS CYANMETHAEMOGLOE BIN)

\begin{tabular}{|c|c|c|c|c|c|}
\hline & (a) & (b) & (c) & (d) & (e) \\
\hline \multicolumn{6}{|c|}{ Precision and Accuracy } \\
\hline $\begin{array}{l}\text { True } \mathrm{Hb} \text { content } \\
(\mathrm{g} / 100 \mathrm{ml})\end{array}$ & $15 \cdot 4$ & $15 \cdot 3$ & $10 \cdot 7$ & $7 \cdot 8$ & 6.0 \\
\hline $\begin{array}{l}\text { As read } \\
\text { (mean of 20) }\end{array}$ & $15 \cdot 17$ & 15.01 & $10 \cdot 37$ & $7 \cdot 44$ & $5 \cdot 76$ \\
\hline $\begin{array}{l}\text { SD } \\
\text { V } \%\end{array}$ & $\begin{array}{l}0 \cdot 2519 \\
1 \cdot 64\end{array}$ & $\begin{array}{l}0 \cdot 3090 \\
2 \cdot 02\end{array}$ & $\begin{array}{l}0 \cdot 3585 \\
3 \cdot 35\end{array}$ & $\begin{array}{l}0 \cdot 3841 \\
4 \cdot 92\end{array}$ & $\begin{array}{l}0 \cdot 2655 \\
4 \cdot 42\end{array}$ \\
\hline \multicolumn{6}{|c|}{$\begin{array}{l}\text { Linearity of Response } \\
\text { Regression line }(y) \\
\text { Correlation coefficient }(r)=0.146 x-0.41\end{array}$} \\
\hline \multicolumn{6}{|c|}{$\begin{array}{l}\text { Comparison with Standardized Photoelectric } \\
\text { observations) }\end{array}$} \\
\hline \multicolumn{6}{|c|}{$\begin{array}{ll}\text { Regression line }(y) & =0.996-0.303 x \\
\text { Correlation coefficient }(r) & =0.9978\end{array}$} \\
\hline
\end{tabular}

\section{EEL Spectra Colorimeter}

Evans Electroselenium Ltd, Halstead, Esse® (£125).

\section{DESIGN}

An attractive, robust and well designed instru ment, $46 \times 23 \mathrm{~cm}$, made of cast aluminium Operation is manual. The controls are easily accessible. There is a continuous spectrum interference filter with wavelength indicator diaf covering the range $400-700 \mathrm{~nm}$ at $35 \mathrm{~nm}$ band widths. There are matched cuvettes in a range of sizes $(0.75 \mathrm{ml}, 1.5 \mathrm{ml}, 3 \mathrm{ml}, 6 \mathrm{ml})$ providing ligh paths of $2.5 \mathrm{~mm}, 5 \mathrm{~mm}, 10 \mathrm{~mm}$, and $20 \mathrm{~mm}$ respectively; single beam with tungsten filament $\overrightarrow{\mathbb{D}}$ Standardization is by one point setting against ab ICSH-approved reference preparation; galvanometer scale measures OD indicated by light spoß and hairline; haemoglobin is obtained by calculation or from a linear graph. After 
stabilization time of 10 minutes there is negligible drift of zero and standard sample during the course of a day.

\section{COMMENTS}

An instrument of acceptable accuracy and precision for routine haemoglobinometry by manual method. The continuous spectrum and range of cuvette sizes makes it a more versatile instrument for use with a wide range of sample concentrations and analytic reactions.

SUMMARY OF ANALYTIC DATA

\begin{tabular}{|c|c|c|c|c|c|}
\hline & (a) & (b) & (c) & (d) & (e) \\
\hline \multicolumn{6}{|c|}{ Precision and Accuracy } \\
\hline $\begin{array}{l}\text { True } \mathrm{Hb} \text { content } \\
(\mathrm{g} / 100 \mathrm{ml})\end{array}$ & $15 \cdot 3$ & $11 \cdot 2$ & 10.7 & 7.8 & 6.0 \\
\hline $\begin{array}{l}\text { As read } \\
\text { (mean of 20) }\end{array}$ & $15 \cdot 29$ & $11 \cdot 28$ & $10 \cdot 70$ & $7 \cdot 70$ & 5.93 \\
\hline $\begin{array}{l}\text { SD } \\
\text { v\% }\end{array}$ & $\begin{array}{l}0.1392 \\
0.91\end{array}$ & $\begin{array}{l}0.1931 \\
1.71\end{array}$ & $\begin{array}{l}0.0883 \\
0.82\end{array}$ & $\begin{array}{l}0 \cdot 1166 \\
1 \cdot 50\end{array}$ & $\begin{array}{l}0.0916 \\
1.54\end{array}$ \\
\hline \multicolumn{6}{|c|}{$\begin{array}{l}\text { Linearity of Response } \\
\text { Regression line }(y) \\
\text { Correlation coefficient }(r)=0.005 x-0.006\end{array}$} \\
\hline \multicolumn{6}{|c|}{$\begin{array}{l}\text { Comparison with Standardized Photoelectric Colorimeter }(x)(100 \\
\text { observations }) \\
\text { Regression line }(y) \quad=0.992 x+0.102 \\
\text { Correlation coefficient }(r)=0.9997\end{array}$} \\
\hline
\end{tabular}

\section{EEL Flowthrough Spectra Colorimeter}

Evans Electroselenium Ltd, Halstead, Essex (£125).

\section{DESIGN}

The instrument is basically similar to the EEL Spectra (q.v.) It is of the same size $(46 \times 23 \mathrm{~cm})$ but in addition it requires the use of a sink or trap bottle for waste from its flow-through cell. The cell consists of a single cuvette of $5 \mathrm{ml}$ capacity; light path $10 \mathrm{~mm}$. An item for criticism is the fact that the flow-through control plunger is difficult to manipulate, making its operation cumbersome.

\section{COMMENTS}

The EEL Spectra colorimeter has been described in the previous section. The flow-through unit is an attachment for facilitating its use. Its design is open to some criticism (see above) but in general it can be recommended as a useful aid for the manual method of haemoglobinometry when there is a relatively large throughput of specimens.
SUMMARY OF ANALYTIC DATA

\begin{tabular}{|c|c|c|c|c|c|}
\hline & (a) & (b) & (c) & $(d)$ & (e) \\
\hline \multicolumn{6}{|c|}{ Precision and Accuracy } \\
\hline $\begin{array}{l}\text { True } \mathrm{Hb} \text { content } \\
(\mathrm{g} / 100 \mathrm{ml})\end{array}$ & $15 \cdot 3$ & $11 \cdot 2$ & $10 \cdot 7$ & $7 \cdot 8$ & $6 \cdot 0$ \\
\hline $\begin{array}{l}\text { As read } \\
\text { (mean of 20) }\end{array}$ & $15 \cdot 29$ & 11.06 & $10 \cdot 60$ & $7 \cdot 67$ & 5.95 \\
\hline $\begin{array}{l}\text { SD } \\
\text { V\% }\end{array}$ & $\begin{array}{l}0.1356 \\
0.88\end{array}$ & $\begin{array}{l}0.1723 \\
1.55\end{array}$ & $\begin{array}{l}0.943 \\
0.88\end{array}$ & $\begin{array}{l}0.1100 \\
1.42\end{array}$ & $\begin{array}{l}0.0943 \\
1.58\end{array}$ \\
\hline
\end{tabular}

Linearity of Response

Regression line $(y) \quad=0.003 x-0.003$

Correlation coefficient $(r)=0.9999$

Comparison with

Regression line $(y) \quad=1.00 x-0.039$

Correlation coefficient $(r)=0.9997$

EEL 171/178 Automatic Colorimeter and Auto-
sampler

Evans Electroselenium Ltd, Halstead, Essex $(£ 1,520)$.

DESIGN

This is a large apparatus consisting of three separate units of the following dimensions: electronic unit $57 \times 45 \mathrm{~cm}$, photometer $48 \times 22$ $\mathrm{cm}$, autosampler $48 \times 41 \mathrm{~cm}$. In practice this will require a bench area of about $120 \times 50 \mathrm{~cm}$. The apparatus is made of aluminium and steel and operation is automatic. There is a continuous spectrum interference filter with wavelength indicator dial covering the range $400-700 \mathrm{~nm}$ at $\frac{3}{\exists}$ $30 \mathrm{~nm}$ bandwidths. It has a single hour-glassshaped cuvette, nominal capacity $2.5 \mathrm{ml}$, light path $5 \mathrm{~mm}$; single beam with tungsten filament. Samples are taken up and subsequently discharged by a motor-driven syringe. Galvanometer scale measures OD; the automatic read-out is a three-digit counter and printer mechanically coupled to a potentiometer, and results are given

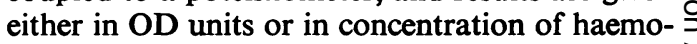
globin $(\mathrm{g} / 100 \mathrm{ml})$ after presetting against an $\frac{T}{O}$ ICSH-approved reference preparation. The printout has specimen identification.

The autosampler holds four racks, each of 12 tubes $(100 \times 15 \mathrm{~cm})$, to contain prediluted samples. As the holding pins are very short the racks are easily dislodged from the autosampler; this may cause accidental spilling of the sample. $\stackrel{0}{\subset}$ Throughput time (rate of analysis) is 18 seconds $\stackrel{D}{\mathscr{D}}$ per sample. After a stabilization time of $30 \stackrel{+}{\circ}$ minutes, zero drift is approximately $1 \%$ per hour, $\frac{0}{0}$ but deviations will be corrected automatically $\vec{D}$ when the auto-zero or auto-standard circuits are $\frac{?}{\mathbb{D}}$ brought into operation.

\section{COMMENTS}

During a one-month testing period the parti- 
cular instrument under trial developed several major faults requiring extensive technical service from the manufacturer on three occasions. There was yet another breakdown during the linearity of response measurements which prevented this test from being completed and the instrument was then returned to the factory.

During preliminary tests it was found that results obtained with Van Kampen-Zijlstra's cyanide-ferricyanide reagent as recommended by ICSH showed considerable discrepancies, in contrast to good performance when a conventional Drabkin's reagent without detergent was used. It seems likely that the discrepancies were caused by frothing and air bubbles. It is not clear whether criticism for this failure of performance should be levelled at the reagent or the instrument. For the present evaluation only conventional Drabkin's reagent was used, and with this an acceptable level of accuracy and precision was obtained.

This is an expensive instrument intended for automatic performance of haemoglobinometry. The faults in the instrument under test made it unacceptable.

SUMMARY OF ANALYTIC DATA

\begin{tabular}{llllll}
\hline & $(a)$ & $(b)$ & $(c)$ & $(d)$ & $(e)$ \\
\hline $\begin{array}{l}\text { Precision and Accuracy } \\
\text { True Hb content }\end{array}$ & 15.3 & 11.2 & 10.7 & 7.8 & 6.0 \\
$\begin{array}{l}\text { (g/100 ml) } \\
\text { As read } \\
\text { (mean of 20) }\end{array}$ & 15.19 & 11.28 & 10.77 & 7.83 & 6.03 \\
SD & 0.1805 & 0.2762 & 0.1876 & 0.1587 & 0.1466 \\
V\% & 1.18 & 2.40 & 1.70 & 2.00 & 2.40
\end{tabular}

Linearity of Response

This was not carried out owing to technical failure (see comment below)

Comparison with Standardized Photoelectric Colorimeter $(x)(100$ observations)

Regression line $(y) \quad=0.980 x+0.329$

Correlation coefficient $(r)=0.9994$

\begin{tabular}{rlll}
\hline & \multicolumn{2}{l}{ Total Carry-over } & \\
\cline { 2 - 3 } & $\begin{array}{l}\text { High } \\
\text { Concentration }\end{array}$ & $\begin{array}{l}\text { Low } \\
\text { Concentration }\end{array}$ & $K=\frac{b_{1}-b_{3}}{a_{3}-b_{3}}$ \\
\hline 1 & 18.1 & 7.3 & 0.0092 \\
2 & 19.0 & 7.7 & 0.0088 \\
3 & 17.7 & 7.8 & 0.0100 \\
4 & 18.4 & 6.4 & 0.0000 \\
5 & 18.2 & 7.7 & 0.0000 \\
6 & 16.9 & 7.6 & 0.0000 \\
7 & 16.1 & 7.0 & 0.0000 \\
8 & 17.5 & 8.2 & 0.0107 \\
9 & 17.3 & 7.9 & 0.0106 \\
10 & 16.3 & 7.9 & 0.0000 \\
& & & Mean of $\mathbf{k}=0.005$ \\
\hline
\end{tabular}

\section{Gallenkamp Mark III Colorimeter}

A. Gallenkamp \& Co Ltd, London EC2 ( $£ 82$; with three filters and three cells).
DESIGN

This is a robust, well designed instrument, $21 \times 0$ $35 \mathrm{~cm}$ in area, made of sheet steel. Operation is manual. It has easily accessible controls. Eight 은 filters are available in the range $450 \mathrm{~nm}-670 \mathrm{~nm}, \overrightarrow{\vec{F}}$ including one at $540 \mathrm{~nm}$. It has matched cuvettes, $\stackrel{\oplus}{\odot}$ $4 \mathrm{ml}-6 \mathrm{ml}$ capacity, with light path of $10 \mathrm{~mm}$; single beam with tungsten filament. Standardiza-흔 tion is by one-point setting by an ICSH-approved $\stackrel{\bar{\omega}}{\rightarrow}$ reference preparation. The galvanometer scale $\stackrel{\mathbb{\Omega}}{\varrho}$ measures OD on a mirror scale with pointer. Haemoglobin is obtained by calculation or from $\vec{A}$ linear graph. After a stabilization time of 10. minutes there is negligible drift of zero and $\vec{\omega}$ standard sample during the course of a day.

\section{COMMENTS}

An instrument of acceptable accuracy and precision suitable for routine haemoglobinometry by 0 manual method.

SUMMARY OF ANALYTIC DATA

\begin{tabular}{|c|c|c|c|c|}
\hline (a) & (b) & (c) & (d) & (e) \\
\hline
\end{tabular}

\begin{tabular}{|c|c|c|c|c|c|}
\hline \multicolumn{6}{|c|}{$\begin{array}{l}\text { Precision and Accuracy } \\
\text { True Hb content }\end{array}$} \\
\hline $\begin{array}{l}(\mathrm{g} / 100 \mathrm{ml}) \\
\text { As read }\end{array}$ & $15 \cdot 3$ & $11 \cdot 2$ & $10 \cdot 7$ & $7 \cdot 8$ & $6 \cdot 0$ \\
\hline $\begin{array}{l}\text { (mean of 20) } \\
\text { SD } \\
V \%\end{array}$ & $\begin{array}{l}15 \cdot 17 \\
0 \cdot 1486 \\
0 \cdot 97\end{array}$ & $\begin{array}{l}11 \cdot 13 \\
0 \cdot 1345 \\
1 \cdot 20\end{array}$ & $\begin{array}{l}10 \cdot 62 \\
0 \cdot 1414 \\
1 \cdot 33\end{array}$ & $\begin{array}{l}7.65 \\
0.1191 \\
1.55\end{array}$ & $\begin{array}{l}5 \cdot 83 \\
0 \cdot 1652 \\
2 \cdot 84\end{array}$ \\
\hline $\begin{array}{l}\text { Linearity of Resp } \\
\text { Regression line ( } \\
\text { Correlation coeffi }\end{array}$ & ent $(r)$ & $\begin{array}{l}0.004 x \\
1.000\end{array}$ & .002 & & \\
\hline
\end{tabular}

Comparison with Standardized Photoelectric Colorimeter $(x)(1000$ observations)

Regression line $(y) \quad=0.992 x+0.102$

Correlation coefficient $(r)=0.9997$

\section{Linson Junior Haemoglobinometer}

A.B. Lars Ljunberg \& Co, Stockholm (distributed by Grant Instruments, Cambridge, £81)

\section{DESIGN}

A compact instrument of attractive design made of moulded plastic; it is $22 \times 14 \mathrm{~cm}$ in size witho accompanying transistorized stabilizer $(17 \times 11 \Phi$ $\mathrm{cm})$. Operation is manual. Its controls are simple ${ }^{+}$ and easily accessible. It has a single cuvette but $a \frac{0}{0}$ flowthrough cuvette is also available. The cuvette $\frac{+}{\mathbb{P}}$ is square, optically flat, with a capacity of $2.5 \mathrm{ml}$ (least volume) to $12.5 \mathrm{ml}$ and a light path of $12.7 \stackrel{\mathrm{Q}}{2}$ $\mathrm{mm}$; single beam with tungsten filament. Stan-O dardization is by one point setting against an ICSH-approved reference preparation. Haemo-o globin is read directly on a galvanometer scale 
indicated by a pointer. Cramped scales make reading difficult, and as the scale is placed horizontally, slight strain occurs when the operator attempts to avoid error of parallax in reading. After stabilization time of five minutes there is negligible drift of zero and a drift of up to $0.0075 \mathrm{OD}$ in a standard sample during the course of a day.

\section{COMMENTS}

A compact, elegant instrument with a fair degree of precision and accuracy. It is one of the cheaper instruments of the type available and it can be recommended, especially for the smaller laboratory or clinic rather than for the laboratory with a heavy workload.

\section{SUMMARY OF ANALYTIC DATA}

\begin{tabular}{|c|c|c|c|c|c|}
\hline & (a) & (b) & (c) & (d) & $(e)$ \\
\hline \multicolumn{6}{|c|}{$\begin{array}{l}\text { Precision and Accuracy } \\
\text { True Hb content }\end{array}$} \\
\hline $\begin{array}{l}(\mathrm{g} / 100 \mathrm{ml}) \\
\text { As read }\end{array}$ & $17 \cdot 4$ & 14.4 & $10 \cdot 0$ & $7 \cdot 3$ & $3 \cdot 8$ \\
\hline $\begin{array}{l}\text { (mean of 20) } \\
\text { SD } \\
V \%\end{array}$ & $\begin{array}{l}17.93 \\
0.2993 \\
1.70\end{array}$ & $\begin{array}{l}14 \cdot 42 \\
0 \cdot 3937 \\
2 \cdot 72\end{array}$ & $\begin{array}{l}10 \cdot 15 \\
0 \cdot 2114 \\
2 \cdot 14\end{array}$ & $\begin{array}{c}7 \cdot 32 \\
0 \cdot 1872 \\
2 \cdot 53\end{array}$ & $\begin{array}{l}3 \cdot 83 \\
0 \cdot 2149 \\
5 \cdot 60\end{array}$ \\
\hline \multicolumn{6}{|c|}{ 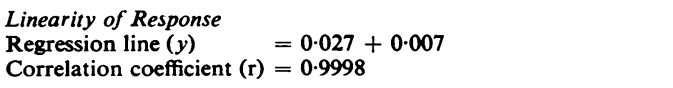 } \\
\hline \multicolumn{6}{|c|}{$\begin{array}{l}\text { Comparison with Standardized Photoelectric Colorimeter }(x)(100 \\
\text { observations }) \\
\text { Regression line }(y) \quad=1.01 x+0.186 \\
\text { Correlation coefficient }(r)=0.9948\end{array}$} \\
\hline
\end{tabular}

\section{Linson 3 Photometer}

A.B. Lars Ljunberg \& Co, Stockholm (distributed by Grant Instruments, Cambridge, f107)

\section{DESIGN}

This instrument occupies an area of $35 \times 29 \mathrm{~cm}$. It is made of painted metal, of attractive design. Operation is manual. The controls are easily accessible. It has a single cuvette but a flowthrough cuvette is also available. The cuvette is square, optically flat, with a capacity of $2.5 \mathrm{ml}$ (least volume) to $12.5 \mathrm{ml}$ and a light path of $12.7 \mathrm{~mm}$; single beam with tungsten filament. Standardization is by one-point setting with an ICSH-approved reference preparation. Results are read as extinction values on galvanometer, indicated by scale pointer. Haemoglobin is obtained by calculation or from a linear graph. Cramped scale makes reading difficult, and as the scale is set horizontally, reading may cause some strain when the operator tries to avoid error of parallax. After a stabilization time of five minutes $\frac{\rho}{\overline{5}}$ there is negligible drift of zero and a drift of up to 0.0075 OD in a standard sample in the course of a day.

COMMENTS
An instrument of acceptable accuracy and precision, suitable for routine haemoglobinometry by manual method. The design of the scale is $\stackrel{\mathbb{D}}{\circ}$ open to criticism.

\section{SUMMARY OF ANALYTIC DATA}

\begin{tabular}{|c|c|c|c|c|c|}
\hline & (a) & (b) & (c) & $(d)$ & (e) \\
\hline \multicolumn{6}{|c|}{$\begin{array}{l}\text { Precision and Accuracy } \\
\text { True Hb content }\end{array}$} \\
\hline $\begin{array}{l}(\mathrm{g} / 100 \mathrm{ml}) \\
\text { As read }\end{array}$ & $17 \cdot 4$ & $14 \cdot 4$ & $10 \cdot 0$ & $7 \cdot 3$ & $3 \cdot 8$ \\
\hline (mean of 20) & $17 \cdot 74$ & $14 \cdot 24$ & $10 \cdot 15$ & $7 \cdot 35$ & 3.90 \\
\hline SD & $0 \cdot 2819$ & 0.1875 & 0.2212 & $0 \cdot 1731$ & 0.1905 \\
\hline$V \%$ & $1 \cdot 60$ & $1 \cdot 35$ & $1 \cdot 12$ & $2 \cdot 30$ & $4 \cdot 90$ \\
\hline \multicolumn{6}{|c|}{$\begin{array}{l}\text { Linearity of Response } \\
\text { Regression line }(y) \\
\text { Correlation coefficient }(r)=0.006 x+0.003\end{array}$} \\
\hline \multicolumn{6}{|c|}{$\begin{array}{l}\text { Comparison with Standardized Photoelectric Colorimeter }(x)(10 \\
\text { observations) }\end{array}$} \\
\hline \multicolumn{4}{|c|}{$\begin{array}{ll}\text { Regression line }(y) & =0.989+0.337 \\
\text { Correlation coefficient }(r) & =0.9956\end{array}$} & & \\
\hline
\end{tabular}

\section{Vitatron HBF 200 Haemoglobinometer}

Distributed by Fisons Ltd (£112; vacuum pump for flowthrough operation f13)

\section{DESIGN}

This instrument has a plastic moulded top with a metal base; it is $28 \times 26 \mathrm{~mm}$ in area and requires additional space for a small vacuum pump and $\frac{\circ}{3}$ trap-bottle. Operation is manual. The working controls are easily accessible but the standardsetting control is very difficult to reach as it is $\frac{7}{0}$ positioned at the bottom of the instrument beneath the cuvette. The cuvette is a single flow- $\mathcal{N}$ through type, requiring prediluted samples. It is N glass in a plastic moulding with a capacity of $\mathrm{N}$ $2.5 \mathrm{ml}$ and a light path of $10 \mathrm{~mm}$. Emptying is achieved by simply applying finger-tip pressure to a hole in the support stand. Standardization is by one-point setting with an ICSH-approved $\stackrel{\Phi}{\circ}$ reference preparation. Haemoglobin is read directly (as $\mathrm{g} / 100 \mathrm{ml}$ cyanmethaemoglobin) on the galvanometer scale. Unusually, the scale is $\frac{\mathbb{D}}{\mathrm{D}}$ marked right to left but it is easy to read except in $\frac{?}{\oplus}$ the $18-20 \mathrm{~g} / 100 \mathrm{ml}$ region where it is cramped. $\varrho$ After a stabilization time of 10 minutes there is slight drift of zero and also in the standard $\delta$ sample during the course of the day, requiring? some adjustment with each batch of specimens. 


\section{COMMENTS}

A neat looking instrument but it requires some redesign of controls. It gives an acceptable performance; it is slightly more expensive than other instruments of this type, but it does not appear to have any significant advantages over the other instruments.

SUMMARY OF ANALYTIC DATA

\begin{tabular}{|c|c|c|c|c|c|}
\hline & (a) & (b) & $(c)$ & (d) & $(e)$ \\
\hline \multicolumn{6}{|c|}{$\begin{array}{l}\text { Precision and Accuracy } \\
\text { True } \mathrm{Hb} \text { content }\end{array}$} \\
\hline $\begin{array}{l}(\mathrm{g} / 100 \mathrm{ml}) \\
\text { As read }\end{array}$ & 15.4 & $15 \cdot 3$ & $10 \cdot 7$ & $7 \cdot 8$ & $6 \cdot 0$ \\
\hline$($ mean of 20$)$ & $15 \cdot 43$ & $15 \cdot 31$ & $10 \cdot 77$ & $7 \cdot 81$ & $6 \cdot 15$ \\
\hline SD & $0 \cdot 1090$ & $0 \cdot 1161$ & $0 \cdot 1360$ & $0 \cdot 1204$ & $0 \cdot 1688$ \\
\hline$V^{0}{ }_{0}$ & 0.71 & 0.76 & $1 \cdot 27$ & $1 \cdot 54$ & $2 \cdot 81$ \\
\hline \multicolumn{6}{|c|}{$\begin{array}{l}\text { Regression line }(y) \\
\text { Correlation coefficient }(r)=0.153+0.005 \\
=0.9999\end{array}$} \\
\hline \multicolumn{6}{|c|}{$\begin{array}{l}\text { Comparison with Stardardized Photoelectric Colorimeter }(x)(100 \\
\text { observations) } \\
\text { Regression line }(y) \quad=0.986 x \cdots 0.148 \\
\text { Correlation coefficient }(r)=0.9980\end{array}$} \\
\hline
\end{tabular}

\section{Vickers Haemoglobinometer}

This instrument is no longer marketed and was not available for testing.

\section{I.L. Haemoglobinometer Model 231}

Instrumentation Laboratories, Lexington Mass., USA.

This is advertised as an automatic instrument for direct measurement of haemoglobin concentration as the combined absorbencies of reduced haemoglobin, oxyhaemoglobin, and carboxyhaemoglobin at $548.5 \mathrm{~nm}$ against a standard red dye consisting of amaranth and $6 \%$ propylene glycol in water. By means of a proportioning pump the blood sample is diluted in a ratio of approximately 1:15 in a 'buffered haemolyzing agent' (as supplied by the manufacturer) and a reading is obtained in less than 15 seconds. There has been one favourable report (Gambino and Waraksa, 1969) but another colleague (G. Izak, personal communication) has commented on serious trouble with the instrument in practice, notably that the lumen of the tubing, which is compressed by the rotating cylinder to obtain the proportional dilution, is subjected to uncontrolled changes, and that this leads to inaccuracies and inconsistencies manifested by $\pm 15 \%$ variation in the same blood sample examined repeatedly within a three-hour period. Moreover, the principle of the instrument is also open to a criticism, at least on theoretical grounds, that its performance cannot be checked directly by means of a cyan- methaemoglobin reference preparation in con $\frac{\varrho}{5}$ formity with current international practice.

Unfortunately, as the UK agents have not ye provided an instrument for evaluation, we have been unable to make personal observations, and its acceptability remains in doubt.

\section{Conclusion}

It is not the purpose of this report to provide 'best buy' recommendation. There have beer previous reports of comparative evaluation of $\overrightarrow{a \omega}$ number of general purpose photoelectric coloris meters (Broughton and Riley, 1965; Broughton? Riley, Cook, Sanders, and Braunsberg, 1966). Ir the present study each instrument has beerio assessed, essentially in terms of its accuracy ancio precision, as to its suitability for haemoglobi-or nometry in the setting of a clinical laboratory응 Undoubtedly, the accuracy of measurement of haemoglobin depends largely upon accuracy in pipetting, sampling, and the correct use of the standard (Lewis and Burgess, 1969). Thus minor? variation in the colorimeter is unlikely to be o⿺ serious consequence and should be put into $\overrightarrow{0}$ perspective. It must, moreover, be remembered that the tests were carried out on one instrument of each make, and that these accuracy and pre-o cision evaluations do not necessarily apply to als other instruments of the same make. Faults mavo occur even when there has been a rigid factoryo inspection; it is important that a 'rogue' instrument should be recognized, and it is suggested that a testing procedure similar to that used in this? study should be applied individually to all newly? purchased instruments.

I wish to thank the manufacturers and their agents who provided the instruments and gaves their willing cooperation. The work was sup-⿳亠丷厂 ported by grants from the Nuffield Provincia 5 Hospital Trust and the Department of Health? and Social Security.

References

Broughton, P. M. G.. and Riley, C. (1965). Colorimeters with flow-through cells. A critical assessment of 4 instruments $N$ Scientific report No. 1, Association of Clinical Biochemists. $\omega$

Broughton, P. M. G., Riley, C., Cook, J. G. H., Sanders, P. G and Braunsberg, H. (1966). Colorimeters: A criticat assessment of 5 commercial instruments. Scientific Repor No. 2, Association of Clinical Biochemists.

Dacie, J. V., and Lewis, S. M. (1968). Practical Hat'matology 4 th ed. pp 39-40. Churchill, London.

Gambino, S. R. . and Waraksa, A. J. (1969). An automatic instru ment for the measurement of haemoglobin concentration Amer. J. clin. Path., 52, 557-560.

International Committee for Standardization in Haematolog: (1967). Recommendations for haemoglobinometry in human blood. Brit. J. Haemat., 13, Suppl.. 71-75.

Lewis, S. M. (1967). Haemoglobinometry by the cyanmethaemor globin method. ACP Broadsheet No. 56.

Lewis, S. M., and Burgess, B. J. (1969). Quality control in haema tology: report of interlaboratory trials in Britain. Brit. me'c J., 4, 253-256. 